\title{
Prostatic Artery Embolization: An Alternative Treatment for Benign Prostatic Hyperplasia
}

\author{
James F. Pike ${ }^{1} \quad$ William F. Abel $^{1} \quad$ Tyler B. Seckel ${ }^{1} \quad$ Christine M.G. Schammel $^{2} \quad$ William Flanagan $^{1,3}$
}

A. Michael Devane 1,4

1University of South Carolina School of Medicine Greenville, Greenville, South Carolina, United States

2Pathology Associates, Greenville, South Carolina, United States

${ }^{3}$ Department of Surgery, Division of Urology, Prisma Health

Upstate, Greenville, South Carolina, United States

${ }^{4}$ Department of Radiology, Interventional Radiology, Prisma Health

Upstate, Greenville, South Carolina, United States

\begin{abstract}
Address for correspondence A. Michael Devane, MD, Prisma Health Upstate, 1201 W Faris Rd, Greenville, South Carolina 29605, United States (e-mail: Mike.devane@prismahealth.org).
\end{abstract}

\begin{abstract}
Keywords

- prostatic artery embolization

- benign prostatic hyperplasia

- prostate volume $>80 \mathrm{~mL}$

Purpose Prostatic artery embolization (PAE) has emerged as a minimally invasive alternative for patients with prostates $>80 \mathrm{~mL}$ and has demonstrated lower morbidity rates. We sought to evaluate PAE at a single tertiary medical center.

Methods A retrospective review of all patients who underwent PAE was completed. Demographic, clinicopathologic, procedure, and outcome data were collected to include international prostatic symptom score (IPSS) and quality of life (QoL) assessments.

Results The pre-PAE mean prostate-specific antigen (PSA) was $8.4 \mathrm{ng} / \mathrm{mL}$, mean prostate volume was $146.9 \mathrm{~mL}(9 \%>200 \mathrm{~mL})$, and mean postvoid residual (PVR) was $208.2 \mathrm{~mL}$ (21.9\% 200-300 mL). IPSS mean was 19.8 and QoL was "mostly dissatisfied." Following PAE, mean PSA was reduced by $3.2 \mathrm{ng} / \mathrm{mL}(38.1 \%, p=0.3014)$, the mean prostate volume reduction was $59.2 \mathrm{~mL}(40.3 \%, n=19, p<0.0001)$, and the average PVR reduction was $150.3 \mathrm{~mL}(72.2 \%, n=27, p=0.0002)$. Average IPSS score was also lower $(11.9 ; 60.1 \%, n=25, p<0.0001)$ and QoL was reduced to "mostly satisfied" ( $p<0.0001$ ). Technical success was $100 \%$ with $24 \%$ minor morbidities.

Conclusion PAE is a successful treatment for patients with BPH resulting in large prostates that are not good candidates for simple prostatectomy, providing optimal care with less operative and postoperative complications.
\end{abstract}

\section{Introduction}

Benign prostatic hyperplasia (BPH) often presents with lower urinary tract symptoms (LUTS) which typically can be medically managed; however, medical refractory LUTS may require surgery. Transurethral resection of the prostate (TURP) has been considered the standard treatment, ${ }^{1}$ but is associated with short-term bleeding and long-term side effects, such as incontinence, dilutional hyponatremia, and sexual dysfunction. It may not be a feasible option in patients with severe comorbidities. ${ }^{2}$ Alternatives to TURP have been developed to treat medical refractory LUTS, including water vapor therapy (Rezum), prostatic urethral lift (UroLift), and photoselective vaporization of the prostate (PVP). These procedures are less invasive, can be performed in the office, have a decreased risk of sexual dysfunction, and have shown considerable efficacy for prostates under $80 \mathrm{~mL} .{ }^{3}$ However, they
DOI https://doi.org/ $10.1055 / \mathrm{s}-0041-1730083$ ISSN 2457-0214 (c) 2021. Indian Society of Vascular and Interventional Radiology.

This is an open access article published by Thieme under the terms of the Creative Commons Attribution-NonDerivative-NonCommercial-License, permitting copying and reproduction so long as the original work is given appropriate credit. Contents may not be used for commercial purposes, or adapted, remixed, transformed or built upon. (https://creativecommons.org/licenses/by-nc-nd/4.0/).

Thieme Medical and Scientific Publishers Pvt. Ltd. A-12, 2nd Floor, Sector 2, Noida-201301 UP, India 
have also been associated with increased retreatment rates when compared to TURP. ${ }^{4}$

For prostates too large to safely utilize TURP $(>80 \mathrm{~mL})$, simple prostatectomy is historically the treatment of choice ${ }^{5}$; however, this surgical procedure is associated with substantial morbidity. ${ }^{6}$ Endoscopic enucleation of the prostate (EEP) is another option for prostates $>80 \mathrm{~mL}$, but it is a technically challenging procedure with a steep learning curve, and patients in many areas of the United States do not have access to a urologist that performs the procedure. ${ }^{7}$ Prostatic artery embolization (PAE) has emerged as an alternative, less invasive option to simple prostatectomy and EEP for patients with large prostates over $80 \mathrm{~mL}$, but data regarding its efficacy are limited. PAE is an interventional radiology technique where the prostatic arteries are embolized utilizing trisacryl gelatin microspheres ${ }^{8}$ resulting in reduced blood supply and prostatic infarction, decreasing overall prostatic volume. PAE was first used as a primary treatment for BPH in two patients in 2009 and showed promising results as an alternative therapy. ${ }^{9}$ Since then, PAE data have shown its effectiveness in patients with prostates too large for TURP and demonstrated lower morbidity rates..$^{10}$ However, PAE is currently only recommended by the American Urological Association (AUA) for patients who have BPH refractory to other medical treatments or as an alternative to surgery in large prostates. ${ }^{10}$ Three randomized control trials compared PAE to TURP, but results between the trials were inconsistent and the sample sizes were small, ${ }^{11-13}$ prompting the guidelines to recommend that the use of PAE for LUTS secondary to BPH should be restricted to the context of clinical trials. ${ }^{14}$ However, the benefits of PAE, especially in prostates that are too large for TURP, appear to be clear. PAE has demonstrated efficacy in relieving the symptoms commonly associated with $\mathrm{BPH},{ }^{15}$ has led to the weaning of catheters and relieving obstructive urinary symptoms in patients with severe urinary flow blockage, ${ }^{15}$ and has been shown to positively affect international prostatic symptom score (IPSS), quality of life (QoL), and Sexual Health Inventory for Men (SHIM). ${ }^{16}$ Specifically, PAE has been correlated with positive clinical outcomes, significantly decreasing the whole prostate gland, median lobe, central gland, and peripheral zone volumes. ${ }^{17}$

Given the benefits purported to PAE as a noninvasive treatment for $\mathrm{BPH}$, we sought to evaluate its use at a single tertiary medical center.

\section{Materials and Methods}

Following institutional review board (IRB) approval, a retrospective review of BPH patients who underwent PAE at a tertiary medical center and were identified by a multidisciplinary team of urologists and interventional radiologists between 9/1/2017 and 8/1/2020 was completed. Patients were included if they were inoperable due to prostate size and/or comorbidity, a poor surgical candidate, or had declined surgery. Additionally, all patients displayed criteria based on AUA guidelines-renal insufficiency, refractory urinary retention, recurrent urinary tract infections (UTIs), or gross hematuria secondary to their $\mathrm{BPH} .{ }^{14}$ Patients with recurrent bladder stones, those for whom LUTS from BPH was refractory to other therapies, or those that declined the use of other therapies were also included. ${ }^{14}$ Patients selected for PAE procedure all had prostates $>80 \mathrm{~mL}$ and were considered poor candidates for surgery due to comorbidities (advanced age, cardiac insufficiencies, severe hepatic disease, frailty, systemic infection, and so forth), desire for a nonsurgical procedure, or request for PAE. Patients with dementia, those unable to complete IPSS or QoL questionnaires, and patients with incomplete medical records were excluded.

Typical demographic and clinicopathologic variables were collected to include pre- and post-PAE prostate-specific antigen (PSA) levels, prostate volume, postvoid residual (PVR), IPSS, QoL, and follow-up. All pre-PAE values were recorded as the last result prior to PAE. PSA values, in conjunction with risk stratification algorithms ${ }^{14}$ for $\mathrm{BPH}$, were used to indicate an increased prostate size. All patients were recommended to have a biopsy per standard protocol. Specifically, if a patient had a suspicious prostate exam, PSA > 10; quickly rising PSA (velocity of $>0.35 \mathrm{ng} / \mathrm{mL}$ per year; a constantly rising PSA while taking a 5-alpha-reductase inhibitor; a family history of prostate cancer; or African-American decent, they were indicated for magnetic resonance imaging (MRI)/biopsy.

Some patients refused. Generally, while PSA $<10$ is considered low risk, ${ }^{18}$ biopsies were still recommended, but most did not have a biopsy pre-PAE.

Prostatic volume was measured with MRI or ultrasound (US; enlarged prostate considered $>80 \mathrm{~mL}$ ) and PVR was measured with bladder ultrasound (PVR $<50 \mathrm{~mL}$ is considered adequate bladder emptying; PVR > $200 \mathrm{~mL}$ indicates inadequate emptying), ${ }^{5,19}$

Embolization was completed as follows. Each $20 \mathrm{~mL}$ syringe of particles (Embospheres $100-300$ or $300-500 \mu \mathrm{m}$ particles; Merit Medical), South Jordan, UT was diluted in $8 \mathrm{~mL}$ Omnipaque contrast (GE Healthcare), Raleigh, NC and then mixed. Embolization proceeded utilizing the radial of femoral arterial (predominant) approach-5 French base catheter was inserted into internal iliac artery and select prostatic arteries with a 2.4 French microcatheter.

IPSS and QoL were measured with questionnaires ( - Table 1, - Table 2)..$^{20}$ IPSS scores ranged from 0 to 35. Data collected post-PAE were variable in time from the procedure with the majority recorded at 1-month follow-up; 3and 6-month follow-up values were recorded if available. Pre- and post-PAE differences in variables such as percent reduction in prostate volume, change in PVR, technical success, catheter dependence, and postoperative (major and minor $)^{21}$ complications were also recorded. Data were analyzed using Fisher $t$-tests and analysis of variance (ANOVA) where appropriate, with 0.05 as significant. The small sample size was considered in all analyses.

\section{Results}

Overall, 34 patients with prostates $>80 \mathrm{~mL}$ that met the AUA guidelines for symptoms secondary to their BPH were evaluated in the study. Mean patient age was 76 years (range 59-92 years) comprised primarily by Caucasians 
Table 1 International prostate symptom score (IPSS) ${ }^{\text {ab }}$

\begin{tabular}{|l|l|l|l|l|l|l|}
\hline In the past month & Not at all & $\begin{array}{l}<1 \text { in } 5 \\
\text { times } \\
\text { time }\end{array}$ & $\begin{array}{l}\text { <Half the } \\
\text { half the } \\
\text { time }\end{array}$ & $\begin{array}{l}\text { About the } \\
\text { time }\end{array}$ & Almost always \\
\hline $\begin{array}{l}\text { 1. Incomplete emptying: How often have } \\
\text { you had the sensation of not emptying your } \\
\text { bladder? }\end{array}$ & 0 & 1 & 2 & 3 & 4 & 5 \\
\hline $\begin{array}{l}\text { 2. Frequency: How often have you had to } \\
\text { urinate less than every two hours? }\end{array}$ & 0 & 1 & 2 & 3 & 4 & 5 \\
\hline $\begin{array}{l}\text { 3: Intermittency: How often have you found } \\
\text { you stopped and started again several times } \\
\text { when you urinated? }\end{array}$ & 0 & 1 & 2 & 3 & 4 & 5 \\
\hline $\begin{array}{l}\text { 4: Urgency: How often have you found it } \\
\text { difficult to postpone urination? }\end{array}$ & 0 & 1 & 2 & 3 & 4 & 5 \\
\hline $\begin{array}{l}\text { 5. Weak stream: How often have you had a } \\
\text { weak urinary stream? }\end{array}$ & 0 & 1 & 2 & 3 & 4 & 5 \\
\hline $\begin{array}{l}\text { 6. Straining: How often have you had to } \\
\text { strain to start urination? }\end{array}$ & 0 & 1 & 2 & 3 & 4 & 5 \\
\hline $\begin{array}{l}\text { 7. Nocturia: How many times did you typi- } \\
\text { cally get up at night to urinate? }\end{array}$ & 0 & 1 & 2 & 3 & 5 \\
\hline
\end{tabular}

${ }^{a}$ Gutman et al. ${ }^{27}$

${ }^{\mathrm{b}}$ All information was self-reported.

Table 2 Quality of life aspect of the international prostate symptom score sab $^{\text {ab }}$

\begin{tabular}{|l|l|l|l|l|l|l|l|}
\hline $\begin{array}{l}\text { Quality of life } \\
\text { due to urinary } \\
\text { symptoms }\end{array}$ & Delighted & Pleased & $\begin{array}{l}\text { Mostly } \\
\text { satisfied }\end{array}$ & Mixed & $\begin{array}{l}\text { Mostly } \\
\text { dissatisfied }\end{array}$ & Unhappy & Terrible \\
\hline $\begin{array}{l}\text { If you were to } \\
\text { spend the rest of } \\
\text { your life with your } \\
\text { urinary condition } \\
\text { just the way it is } \\
\text { now, how would } \\
\text { you feel about } \\
\text { that? }\end{array}$ & 0 & 1 & 2 & 3 & 4 & 5 & 6 \\
\hline
\end{tabular}

${ }^{2} 27$.

${ }^{\mathrm{b}}$ All information was self-reported.

( $n=32 ; 91.2 \%$ ), with $2.9 \%$ African-American $(n=1)$ and $5.9 \%$ Hispanic ( $n=2$; - Table 3 ). Average body mass index (BMI) was 28.2 (range $20.8-38.1$ ) and $50 \%$ of the cohort was classified as overweight (BMI 25-29.9), with $32.4 \%$ classified as obese (BMI $>30^{22}$; - Table 3 ). The most frequent comorbidity of the cohort was hypertension ( $n=26$; 76.5\%; data not shown). Overall, seven patients had PSA > 10 pre-PAE and had biopsies. Four other patients had MRI PI-RADS 3 lesions and also had biopsies pre-PAE.

Prior to treatment, BPH indicators were evaluated $(n=$ 32; - Table 4). The mean PSA of the cohort was $8.4 \mathrm{ng} / \mathrm{mL}$ $(n=32 ; n=7$ PSA $>10)$. Patients with $<5 \mathrm{ng} / \mathrm{mL}$ made up $50 \%$ of this cohort ( $n=16$ ), with $28 \%$ having a PSA between 5 and $10 \mathrm{ng} / \mathrm{mL}$. Pre-PAE mean prostate volume was $146.9 \mathrm{~mL}$ ( $n=32$ ), with $12.5 \%$ of the cohort having $<100 \mathrm{~mL}(n=4)$, $43.8 \% 100$ to $150 \mathrm{~mL}(n=14), 34.4 \%$ at 150 to $200 \mathrm{~mL}(n=11)$, and the largest prostate volumes ( $>200 \mathrm{~mL}$ ) comprising $9.4 \%$ ( $n=3$; -Table 4). Mean PVR for the group was $208.2 \mathrm{~mL}$ $(n=32)$, with the largest cohort $(n=10 ; 31.2 \%)$ retaining $<100 \mathrm{~mL}$ and the second largest group $(n=9 ; 28.1 \%)$ retaining between 100 and $200 \mathrm{~mL}$. Those with 200 to $300 \mathrm{~mL}$
PVR comprised $21.9 \%(n=7)$ and those with $>300 \mathrm{~mL}$ made up $18.8 \%$ of the group ( $n=6$; - Table 4 ). IPSS scores had a mean of $19.8(n=28)$ pre-PAE, with only three patients reporting a score $<10$ (10.7\%), 10 between 10 and 20 (35.7\%), and 16 scoring $>20$ (53.6\%) (-Table 4).

The mean QoL reported by pre-PAE patients was 4.5 (mostly dissatisfied; $n=32$; - Table 4 ), with the majority reporting being unhappy or having a terrible QoL due to their $\mathrm{BPH}(59.4 \% ; n=19)$. A mixed view or mostly dissatisfied quality of life was reported by $34.4 \%$ of patients $(n=11)$ and only two patients reported that they were pleased or mostly satisfied (6.2\%).

Post-PAE BPH indicators were also evaluated (- Table 4). The mean PSA was $5.2 \mathrm{ng} / \mathrm{mL}(n=12)$, with $75 \%$ of the cohort having $<5 \mathrm{ng} / \mathrm{mL}$ and only one patient with a PSA of $>20 \mathrm{ng} / \mathrm{mL}$. The mean prostate volume of the post-PAE group was $87.7 \mathrm{~mL}(n=20$; - Table 4$)$, with $80 \%(n=16)$ having prostates $<100 \mathrm{~mL}$ and $20 \%$ with 100 to $200 \mathrm{~mL}(n=4)$; none of the cohort had prostates $>150 \mathrm{~mL}$. Post-PAE mean PVR was $57.9 \mathrm{~mL}(n=28)$ with $85.7 \%$ reporting residual $<100 \mathrm{~mL}$; only one patient had a post-PAE PVR between 200 and $300 \mathrm{~mL}$ 
Table 3 Demographics

\begin{tabular}{|l|l|}
\hline$n=34$ & Total (\%) \\
\hline Age (years) & \\
\hline Mean & 76 \\
\hline Range & $59-92$ \\
\hline$x<65$ & 1 \\
\hline $65<x<70$ & 2 \\
\hline $70<x<75$ & 12 \\
\hline $75<x<80$ & 11 \\
\hline $80<x<85$ & 2 \\
\hline$x>85$ & 6 \\
\hline Race & \\
\hline Caucasian & 31 \\
\hline African- & 1 \\
\hline American & \\
\hline Other & 2 \\
\hline BMla & \\
\hline Mean & 28.2 \\
\hline Range & $20.78-38.06$ \\
\hline$x<18.5$ & 0 \\
\hline $18.5<x<25$ & 6 \\
\hline $24.9<x<30$ & 17 \\
\hline $29.9<x<35$ & 9 \\
\hline $34.9<x<40$ & 2 \\
\hline$x>40$ & 0 \\
\hline
\end{tabular}

aBody Mass Index; categories obtained from cdc.gov; accessed 9/1/2020 Centers for Disease Control and Prevention ${ }^{22}$.

and no patients had $>300 \mathrm{~mL}$ retention ( - Table 4 ). Patients reported a more favorable IPSS (mean 7.9; $n=27$; - Table 4) post-PAE, with $66.7 \%<10$ and $29.6 \%$ between 10 and 20 ; only one IPSS was $>20$. Patient-reported QoL $(n=26)$ was more favorable post-PAE (mean 1.5; - Table 4 ) as $84.6 \%$ of patients reported that they were pleased or mostly satisfied $(n=22)$, $11.5 \%(n=3)$ reported having a mixed view of life or were mostly dissatisfied, and only one patient (3.8\%) reported being unhappy or having a terrible quality of life due to $\mathrm{BPH}$.

There was an average reduction of PSA by $3.2 \mathrm{ng} / \mathrm{mL}$ (38.1\%, $n=12, \mathrm{p}=0.3014$; - Table 5) after PAE. The average decrease in prostatic volume was $59.2 \mathrm{~mL}(40.3 \%, n=19$, $p<0.0001$ ) with the average PVR reduction of $150.3 \mathrm{~mL}$ $(72.2 \%, n=27, p=0.0002)$. IPSS score was reduced an average of $11.9(60.1 \%, n=25, p<0.0001)$, with average QoL reduction of $3.0(66.7 \%, n=26, p<0.0001$; - Table 5$)$.

Catheter dependence was noted in $35 \%$ of patients prior to PAE ( $n=12$, data not shown). Out of those 12 patients, 11 (91.7\%) did not require the use of a catheter post-PAE.

TURP was performed for further LUTS for two patients after PAE (6\%) and one patient had a simple prostatectomy (3\%; data not shown) for insufficient relief of symptoms. A technical success rate of $100 \%$ was achieved (catheterization and embolization of at least one pelvic side), with 76.5\%
( $n=26$ ) bilateral embolization (-Table 6). Out of the eight patients who received unilateral embolization, $37.5 \%(n=3)$ had unsuccessful embolization of one side due to tortuous or occluded prostatic or collateral vessels, $25 \%(n=2)$ had renal insufficiency, and $12.5 \%(n=1)$ did not have a left prostatic artery presumably due to surgical ligation. In comparison of patients who underwent unilateral versus bilateral embolization (-Table 6), there were no significant differences in age, prostate volume, PVR, IPSS, and QoL. Six out of eight patients with unilateral embolization did not require further therapy due to clinical success. Out of the other two patients, one had insufficient relief of symptoms with unilateral procedure requiring further embolization. The other patient was staged to have embolization of the other side one month later due to procedure length, contrast dose, and radiation exposure.

Overall, minor complications were reported in $23.5 \%$ patients ( $n=8$; - Table 6 ) with hematuria most frequently reported ( $n=4 ; 50 \% ; 12 \%$ of all PAE), followed by acute urinary retention ( $n=3 ; 37.5 \%$; $9 \%$ of the total group), UTI in two (25\%; $6 \%$ of the PAE patients), and external iliac artery dissection in one (12.5\%; $3 \%$ of the total cohort). One patient had both acute urinary retention and hematuria, and another patient had both UTI and hematuria. The external iliac artery dissection was repaired with self-expandable stent and the patient was discharged the next day with no future complications. The remainder of minor complications mentioned resolved without any additional intervention.

\section{Discussion}

The prevalence of BPH increases with age, and life expectancy and population aging are increasing worldwide. ${ }^{23,24}$ According to data from "World Population Prospects: the 2019 Revision," by 2050 , the amount of people in the world older than 65 years will have increased from 1 in 11 to 1 in $6,{ }^{23,24}$ increasing the number of patients with BPH and other age-related comorbidities. PAE for the treatment of BPH is an alternative for patients with significant comorbidities or are otherwise poor candidates for surgery. Here we present the clinical outcomes of 34 patients with prostate volumes over $80 \mathrm{~mL}$ who underwent PAE for $\mathrm{BPH}$ in terms of changes in PSA, prostatic volume, PVR, IPSS scores, and QoL scores. Notable comorbidities in this cohort included elevated BMI and hypertension pre-PAE, which have both been reported as risk factors for BPH. ${ }^{25,26}$ Additionally, 91.7\% patients who were catheter dependent pre-PAE were able to void independently without a catheter post-PAE, similar to reported literature. ${ }^{15}$ While typically, patients with IPSS $<10$ are considered to have mild LUTS and do not usually require treatment, three of the patients in our study had IPSS $<10$ but also a high QoL score, high PVR, high prostate volume, or a combination of these factors, leading to PAE treatment. ${ }^{27}$ The technical success of the procedure was $100 \%$, also similar to the literature. ${ }^{28}$ There was improvement in all values measured in the study, and these data demonstrate that PAE effectively improves patient satisfaction, decreases symptoms, and objectively reduces PVR and prostate volume. 
Table 4 Pre-and post-PAE BPH indicators ${ }^{\mathrm{a}}$

\begin{tabular}{|c|c|c|c|c|}
\hline & $\begin{array}{l}\text { Pre-PAE } \\
\mathrm{n}(\%)\end{array}$ & $\begin{array}{l}\text { Post-PAE } \\
\text { n (\%) }\end{array}$ & Change & $p$-Value \\
\hline PAE PSA (ng/mL) & $n=32$ & $n=12$ & & \\
\hline Mean & 8.4 & 5.2 & -3.2 & 0.3014 \\
\hline$x<5$ & $16(50)$ & $9(75)$ & -7 & 0.1405 \\
\hline $5<x<10$ & $9(28.1)$ & $1(8.3)$ & -8 & 0.1675 \\
\hline $10<x<15$ & $3(9.4)$ & $1(8.3)$ & -2 & 0.9111 \\
\hline $15<x<20$ & $2(6.2)$ & $0(0)$ & -2 & 0.3829 \\
\hline$x>20$ & $2(6.2)$ & $1(8.3)$ & -1 & 0.8072 \\
\hline Prostate volume $(\mathrm{mL})$ & $n=32$ & $n=20$ & & \\
\hline Mean & 146.9 & 87.7 & -59.2 & $<0.0001$ \\
\hline$x<100$ & $4(12.5)$ & $16(80)$ & +12 & $<0.0001$ \\
\hline $100<x<150$ & $14(43.8)$ & $4(20)$ & -10 & 0.0823 \\
\hline $150<x<200$ & $11(34.4)$ & $0(0)$ & -11 & 0.0034 \\
\hline$x>200$ & $3(9.4)$ & $0(0)$ & -3 & 0.1618 \\
\hline PVR (mL) & $n=32$ & $n=28$ & & \\
\hline Mean & 208.2 & 57.9 & -150.3 & 0.0002 \\
\hline $0<x<100$ & $10(31.2)$ & $24(85.7)$ & +14 & $<0.0001$ \\
\hline $100<x<200$ & $9(28.1)$ & $3(10.7)$ & -6 & 0.0954 \\
\hline $200<x<300$ & 7 (21.9) & $1(3.6)$ & -6 & 0.0393 \\
\hline$x>300$ & $6(18.8)$ & $0(0)$ & -6 & 0.0165 \\
\hline IPSS & $n=\mathbf{2 8}$ & $n=27$ & & \\
\hline Mean & 19.8 & 7.9 & -11.9 & $<0.0001$ \\
\hline$x<10$ & $3(10.7)$ & $18(66.7)$ & +15 & $<0.0001$ \\
\hline $10<x<20$ & $10(35.7)$ & $8(29.6)$ & -2 & 0.6329 \\
\hline$x>20$ & $15(53.6)$ & $1(3.7)$ & -14 & 0.0001 \\
\hline QoL & $n=32$ & $n=26$ & & \\
\hline Mean & 4.5 & 1.5 & -3.0 & $<0.0001$ \\
\hline$x=1,2$ & $2(6.2)$ & $22(84.6)$ & +20 & $<0.0001$ \\
\hline$x=3,4$ & $11(34.4)$ & $3(11.5)$ & -8 & 0.0445 \\
\hline$x=5,6$ & 19 (59.4) & $1(3.8)$ & -18 & $<0.0001$ \\
\hline
\end{tabular}

avariables were not available for all patients due to individual urology practice guidelines.

Abbreviations: BPH, benign prostatic hyperplasia; IPSS, international prostatic symptom score; PAE, prostatic artery embolization; PSA, prostate-specific antigen; PVR, postvoid residual; QoL, quality of life survey.

Table 5 Summary of cohort change pre- versus post-PAE

\begin{tabular}{|l|l|l|l|l|l|l|l|l|l|}
\hline \multicolumn{4}{|c|}{ Average difference } & \multicolumn{3}{c|}{ \% Reduction } \\
\hline $\begin{array}{l}\text { PSA (ng/ } \\
\mathrm{mL})\end{array}$ & $\begin{array}{l}\text { Volume } \\
(\mathrm{mL})\end{array}$ & PVR $(\mathrm{mL})$ & IPSS & QoL & $\begin{array}{l}\text { PSA }(\mathrm{ng} / \\
\mathrm{mL})\end{array}$ & $\begin{array}{l}\text { Volume } \\
(\mathrm{mL})\end{array}$ & PVR $(\mathrm{mL})$ & IPSS & QoL \\
\hline-3.2 & -59.2 & -150.3 & -11.9 & -3.0 & 38.1 & 40.3 & 72.2 & 60.1 & 66.7 \\
\hline
\end{tabular}

Abbreviations: IPSS, international prostatic symptom score; PAE, prostatic artery embolism; PSA, prostate-specific antigen; PVR, postvoid residual; QoL, quality of life survey.

aVariables were not available for all patients due to individual urology practice guidelines.

In addition to these measures, it is important to understand other benefits associated with PAE compared to procedures like simple prostatectomy, EEP, and TURP. PAE is usually performed on an outpatient basis, while most patients undergoing TURP, EEP, or simple prostatectomy stay at least 1 or 2 days post procedure. ${ }^{28,29}$ Patients who have had PAE also report significantly shorter time to return to normal activities compared to TURP, and some studies have shown less adverse events with PAE. ${ }^{13,30}$ When compared to simple prostatectomy, PAE has less operative and postoperative 
Table 6 Unilateral versus bilateral embolization ${ }^{\mathrm{a}}$

\begin{tabular}{|c|c|c|c|c|c|}
\hline & & Total $n=34$ & Unilateral $n=8$ & Bilateral $n=26$ & $p$-Value \\
\hline \multirow[t]{2}{*}{ Age } & Mean & 76 & 79 & 75 & 0.1600 \\
\hline & Range & $59-92$ & $70-88$ & $59-92$ & \\
\hline \multirow[t]{5}{*}{ PSA } & & $n=32$ & $n=7$ & $n=25$ & \\
\hline & Pre & 8.4 & 5.1 & 9.4 & 0.3137 \\
\hline & & $n=12$ & $n=1$ & $n=11$ & \\
\hline & Post & 5.2 & 1 & 5.5 & \\
\hline & \% Reduction & 38.1 & 80.4 & 41.5 & 0.0580 \\
\hline \multirow[t]{5}{*}{ Prostate volume } & & $n=32$ & $n=8$ & $n=24$ & \\
\hline & Pre & 146.9 & 152.5 & 145.0 & 0.6483 \\
\hline & & $n=20$ & $n=4$ & $n=16$ & \\
\hline & Post & 87.7 & 73.5 & 91.3 & 0.1749 \\
\hline & \% Reduction & 40.3 & 51.8 & 37.0 & 0.4625 \\
\hline \multirow[t]{5}{*}{$\mathrm{PVR}^{\mathrm{b}}$} & & $n=32$ & $n=7$ & $n=25$ & \\
\hline & Pre & 208.2 & 157 & 222.5 & 0.4353 \\
\hline & & $n=28$ & $n=7$ & $n=21$ & \\
\hline & Post & 57.9 & 32.4 & 66.4 & 0.1602 \\
\hline & \% Reduction & 72.2 & 79.4 & 70.2 & 0.6162 \\
\hline \multirow[t]{5}{*}{ IPSS } & & $n=28$ & $n=6$ & $n=22$ & \\
\hline & Pre & 19.8 & 14.8 & 21.1 & 0.0804 \\
\hline & & $n=27$ & $n=6$ & $n=21$ & \\
\hline & Post & 7.9 & 9 & 7.6 & 0.5993 \\
\hline & \% Reduction & 60.1 & 39.2 & 64.0 & 0.2205 \\
\hline \multirow[t]{15}{*}{ QoL } & & $n=32$ & $n=8$ & $n=24$ & \\
\hline & Pre & 4.5 & 4 & 4.7 & 0.1634 \\
\hline & & $n=26$ & $n=5$ & $n=21$ & \\
\hline & Post & 1.5 & 1 & 1.6 & 0.3126 \\
\hline & \% Reduction & 66.7 & 75 & 66.0 & 0.6379 \\
\hline & Reason for unilateral $^{\mathrm{c}}$ & $n=8$ & $n=8$ & & \\
\hline & Occluded vessels & $3(38 \%)$ & $3(38 \%)$ & & \\
\hline & Renal insufficiency & $2(25 \%)$ & $2(25 \%)$ & & \\
\hline & No L prostatic artery & $1(12 \%)$ & $1(12 \%)$ & & \\
\hline & Bilateral later & $2(25 \%)$ & $2(25 \%)$ & & \\
\hline & Complications ${ }^{\mathrm{de}}$ & $n=8$ & $n=8$ & $n=26$ & \\
\hline & Hematuria & 4 & 2 & 2 & \\
\hline & Acute urinary retention & 3 & 0 & 3 & \\
\hline & UTI & 2 & 0 & 2 & \\
\hline & External iliac artery dissection & 1 & 0 & 1 & \\
\hline
\end{tabular}

Abbreviations: IPSS, international prostatic symptom score; PSA, prostate-specific antigen; PVR, postvoid residual; QoL, quality of life survey. ${ }^{a}$ All patients that underwent PAE had a successful procedure (100\%).

bPVR went up in the bilateral patients, however, there is inherent poor reliability in this calculation due to collection procedures.

'The reasons that a unilateral procedure was completed was due to occluded prostatic vessel.

dTwenty-four percent of patients that underwent PAE $(n=34)$ had a complication.

ePatients may have had more than one complication. 
Table 7 Literature comparison

\begin{tabular}{|l|l|l|l|l|l|l|l|}
\hline Reduction \% & $\begin{array}{l}\text { Pike }^{\mathrm{a}} \\
(\mathrm{PAE})\end{array}$ & $\begin{array}{l}\text { Westwood }^{\mathrm{b}} \\
(\text { Rezum) }\end{array}$ & $\begin{array}{l}\text { Rukstalis }^{\mathrm{b}} \\
\text { (UroLift) }\end{array}$ & $\begin{array}{l}\text { Rieken }^{\mathrm{b}} \\
\text { (PVP) }\end{array}$ & $\begin{array}{l}\text { Jones }^{\mathrm{c}} \\
(\text { HoLEP) }\end{array}$ & $\begin{array}{l}\text { Jones }^{\mathrm{c}} \\
\text { (simple prostatectomy) }\end{array}$ & $\begin{array}{l}\text { Zell }^{\mathrm{d}} \\
(\mathrm{HoLEP}>\mathbf{2 0 0} \mathrm{mL})\end{array}$ \\
\hline PSA & 38.1 & & & $42-43$ & & & 90 \\
\hline Vol (mL) & 40.3 & & & & & & \\
\hline PVR & 72.2 & $5-35$ & 8.4 & $65-100$ & 98 & 98 & 63 \\
\hline IPSS & 60.1 & $45-58$ & 50.9 & $55-73$ & $58-90$ & $61-89$ & 43 \\
\hline QOL & 66.7 & $38-61$ & 49.6 & $50-60$ & 58 & 66 & \\
\hline
\end{tabular}

Abbreviations: IPSS, international prostatic symptom score; PSA, prostate-specific antigen; vol, volume; PVR, postvoid residual; QoL, quality of life survey.

${ }^{a}$ All prostates in this study were $>80 \mathrm{~mL}$.

bProstates were $<80 \mathrm{~mL}$.

cProstates were 115-125 mL

dProstates were $>200 \mathrm{~mL}$; other studies ${ }^{33-37}$ did not assess change in prostate volume.

complications. ${ }^{31}$ In our study, there were no major complications and $23.5 \%$ patients experienced minor complications. ${ }^{21}$

Additionally, eight of the 34 patients in our study received unilateral embolization, and their results in every category were not statistically different than those with bilateral. Two out of the eight did receive embolization of the contralateral side within 2 months of first PAE due to persistent symptoms. This is a small sample size of patients who received unilateral embolization, but it shows that perhaps, as has been suggested by other studies, bilateral embolization is not necessarily required to achieve adequate results. 20,29,32

Recent studies have also been performed analyzing the effects of Rezum, UroLift, and PVP therapies on IPSS and QoL scores. Rezum has been reported through multiple studies to decrease PVR between 5 and 35\%, IPSS between 45 and 58\%, and QoL by 38 to $61 \%{ }^{33}$ UroLift data showed an $8.4 \%$ reduction in PVR, 50.9\% reduction in IPSS, and a $49.6 \%$ reduction of QoL. ${ }^{34}$ PVP results from multiple studies have shown a reduction in PVR by 65 to $100 \%$, IPSS by 55 to $73 \%$, and QoL by 50 to $60 \%{ }^{35}$ Our data portray similar improvement in large prostates over $80 \mathrm{~mL}$ for these measures, whereas the prostatic volume used in these studies was $<80 \mathrm{~mL}$ ( - Table 7 ).

When looking at enucleation procedures and simple prostatectomy performed on larger prostates $>80 \mathrm{~mL}$, our data also show similar outcomes. A systematic review and meta-analysis regarding holmium laser enucleation of the prostate (HoLEP) and simple prostatectomy included multiple studies of patients with mean prostate volumes between 110 and $125 \mathrm{~mL}$. HoLEP led to a decrease in IPSS by 58 to $90 \%$ and QoL by $58 \%$. Simple prostatectomy decreased IPSS by 61 to $89 \%$ and QoL by $66 \%{ }^{36}$ In a study on the use of HoLEP in prostates over $200 \mathrm{~mL}$, IPSS was reduced by $63 \%$ and QoL by $43 \%$ (-Table 7). ${ }^{37}$

At our institution, PAE has produced results similar to performing TURP, Rezum, UroLift, and PVP on prostates $<80 \mathrm{~mL}$ and to enucleation and simple prostatectomy on prostates $>80 \mathrm{~mL}$. These data support the use of PAE in large prostates $>80 \mathrm{~mL}$ and in patients who are poor surgical candidates, or who desire a less invasive procedure than simple prostatectomy. In some cases, PAE could be used to shrink the prostate small enough to perform TURP, Rezum, UroLift, or PVP. Two of our patients had a TURP after PAE for the treatment of LUTS.
This result should not be considered a failure, as ultimately, those patients were able to treat their large prostate without using simple prostatectomy. Our study limitations include the retrospective nature of the study, the small sample size, and short follow-up intervals. More studies should be performed on PAE before it is implemented as a routine treatment for BPH-LUTS in patients with large prostates.

\section{Conclusion}

Our study demonstrates that PAE is a safe, effective procedure for the treatment of BPH-related LUTS in patients with prostates larger than $80 \mathrm{~mL}$. Additionally, PAE is often the only safe treatment option for some patients with large prostates due to comorbidities. Although limited by small sample size $(n=8)$, it appears that unilateral PAE could be adequate for some patients suggesting the feasibility of a unilateral embolization to limit procedural complications. A research study involving a larger patient cohort followed over a longer postprocedure time would be helpful to substantiate this observation.

\section{Conflict of Interest}

M.D. is a paid consultant for Boston Scientific and speaker for Ethicon/Johnson and Johnson.

He also reports personal fees from Boston Scientific and from Johnson and Johnson/Ethicon, outside the submitted work.

All other authors declare they have no conflicts of interest.

\section{Ethical Approval}

For this type of study, formal consent is not required.

\section{Informed Consent}

This study has obtained IRB approval from Health Sciences, South Carolina, and the need for informed consent was waived.

\section{References}

1 Oelke M, Bachmann A, Descazeaud A, et al. European Association of Urology. EAU guidelines on the treatment and follow-up of non-neurogenic male lower urinary tract 
symptoms including benign prostatic obstruction. Eur Urol 2013;64(1):118-140

2 Kirby M, Chapple C, Jackson G, et al. Erectile dysfunction and lower urinary tract symptoms: a consensus on the importance of co-diagnosis. Int J Clin Pract 2013;67(7):606-618

3 Cornu JN, Ahyai S, Bachmann A, et al. A systematic review and meta-analysis of functional outcomes and complications following transurethral procedures for lower urinary tract symptoms resulting from benign prostatic obstruction: an update. Eur Urol 2015;67(6):1066-1096

4 Yu X, Elliott SP, Wilt TJ, McBean AM. Practice patterns in benign prostatic hyperplasia surgical therapy: the dramatic increase in minimally invasive technologies. J Urol 2008;180(1):241-245

5 Ou R, You M, Tang P, Chen H, Deng X, Xie K. A randomized trial of transvesical prostatectomy versus transurethral resection of the prostate for prostate greater than $80 \mathrm{~mL}$. Urology 2010;76(4):958-961

6 Gratzke C, Schlenker B, Seitz M, et al. Complications and early postoperative outcome after open prostatectomy in patients with benign prostatic enlargement: results of a prospective multicenter study. J Urol 2007;177(4):1419-1422

7 Enikeev D, Morozov A, Taratkin M, et al. Systematic review of the endoscopic enucleation of the prostate learning curve. World J Urol 2020. Doi: 10.1007/s00345-020-03451-1

8 Carnevale FC, Moreira AM, Antunes AA. The "PErFecTED technique": proximal embolization first, then embolize distal for benign prostatic hyperplasia. Cardiovasc Intervent Radiol 2014;37(6):1602-1605

9 Carnevale FC, Antunes AA, da Motta Leal Filho JM, et al. Prostatic artery embolization as a primary treatment for benign prostatic hyperplasia: preliminary results in two patients. Cardiovasc Intervent Radiol 2010;33(2):355-361

10 Pisco J, Bilhim T, Pinheiro LC, et al. Prostate embolization as an alternative to open surgery in patients with large prostate and moderate to severe lower urinary tract symptoms. J Vasc Interv Radiol 2016;27(5):700-708

11 Carnevale FC, Iscaife A, Yoshinaga EM, Moreira AM, Antunes AA, Srougi M. Transurethral resection of the prostate (TURP) versus original and PErFecTED prostate artery embolization (PAE) due to benign prostatic hyperplasia $(\mathrm{BPH})$ : preliminary results of a single center, prospective, urodynamic-controlled analysis. Cardiovasc Intervent Radiol 2016;39(1):44-52

12 Gao YA, Huang Y, Zhang R, et al. Benign prostatic hyperplasia: prostatic arterial embolization versus transurethral resection of the prostate-a prospective, randomized, and controlled clinical trial. Radiology 2014;270(3):920-928

13 Abt D, Hechelhammer L, Müllhaupt G, et al. Comparison of prostatic artery embolisation (PAE) versus transurethral resection of the prostate (TURP) for benign prostatic hyperplasia: randomised, open label, non-inferiority trial. BMJ 2018;361:k2338

14 Parsons JK, Barry MJ, Dahm P, et al. Benign Prostatic Hyperplasia: Surgical Management of Benign Prostatic Hyperplasia/Lower Urinary Tract Symptoms (2018, Amended 2019, 2020). American Urological Association;2020 1-35

15 Yu SCH, Cho CC, Hung EHY, Chiu PKF, Yee CH, Ng CF. Prostate artery embolization for complete urinary outflow obstruction due to benign prostatic hypertrophy. Cardiovasc Intervent Radiol 2017;40(1):33-40

16 Pisco JM, Bilhim T, Pinheiro LC, et al. Medium- and long-term outcome of prostate artery embolization for patients with benign prostatic hyperplasia: results in 630 patients. J Vasc Interv Radiol 2016;27(8):1115-1122

17 Lin YT, Amouyal G, Correas JM, et al. Can prostatic arterial embolisation (PAE) reduce the volume of the peripheral zone? MRI evaluation of zonal anatomy and infarction after PAE. Eur Radiol 2016;26(10):3466-3473
18 National Comprehensive Cancer Network. Prostate cancer (version 4.2019). https://www.nccn.org/patients/guidelines/ content/PDF/prostate-patient.pdf. Accessed August 30, 2020

19 Ballstaedt L, Woodbury B. Bladder Post Void Residual Volume. StatPearls Publishing. 2020. https://www.ncbi.nlm.nih.gov/ books/NBK539839/. Accessed August 30, 2020

20 Young S, Golzarian J. Prostate embolization: patient selection, clinical management and results. CVIR Endovasc 2019;2(1):7

21 Khalilzadeh O, Baerlocher MO, Shyn PB, et al. Proposal of a New Adverse Event Classification by the Society of Interventional Radiology Standards of Practice Committee. J Vasc Interv Radiol 2017;28(10):1432-1437.e3

22 Centers for Disease Control and Prevention. All About Adult BMI. 2020. https://www.cdc.gov/healthyweight/assessing/ bmi/adult_bmi/index.html. Accessed August 30, 2020

23 United Nations, Department of Economic and Social Affairs, Population Division. World Population Prospects 2019: Highlights.ST/ESA/SER.A/423.2019. https://population.un.org/ wpp/Publications/Files/WPP2019_Highlights.pdf. Accessed August 30, 2020

24 Lee SWH, Chan EMC, Lai YK. The global burden of lower urinary tract symptoms suggestive of benign prostatic hyperplasia: a systematic review and meta-analysis. Sci Rep 2017;7(1):7984

25 Parikesit D, Mochtar CA, Umbas R, Hamid ARH. The impact of obesity towards prostate diseases. Prostate Int 2016;4(1):1-6

26 Hwang EC, Kim SO, Nam DH, et al. Men with hypertension are more likely to have severe lower urinary tract symptoms and large prostate volume. Low Urin Tract Symptoms 2015;7(1):32-36

27 Gutman S, Merrick GS, Butler WM, et al. Severity categories of the International Prostate Symptom Score before, and urinary morbidity after, permanent prostate brachytherapy. BJU Int 2006;97(1):62-68

28 Somani BK, Hacking N, Bryant T, et al. Prostate artery embolization (PAE) for benign prostatic hyperplasia (BPH) BJU Int 2014;114(5):639-640

29 Bilhim T, Pisco J, Rio Tinto $\mathrm{H}$, et al. Unilateral versus bilateral prostatic arterial embolization for lower urinary tract symptoms in patients with prostate enlargement. Cardiovasc Intervent Radiol 2013;36(2):403-411

30 Ray AF, Powell J, Speakman MJ, et al. Efficacy and safety of prostate artery embolization for benign prostatic hyperplasia: an observational study and propensity-matched comparison with transurethral resection of the prostate (the UK-ROPE study) BJU Int 2018;122(2):270-282

31 Pariser JJ, Pearce SM, Patel SG, Bales GT. National trends of simple prostatectomy for benign prostatic hyperplasia with an analysis of risk factors for adverse perioperative outcomes. Urology 2015;86(4):721-725

32 Cizman Z, Isaacson A, Burke C. Short- to midterm safety and efficacy of prostatic artery embolization: a systematic review. J Vasc Interv Radiol 2016;27(10):1487-1493.e1

33 Westwood J, Geraghty R, Jones P, Rai BP, Somani BK. Rezum: a new transurethral water vapour therapy for benign prostatic hyperplasia. Ther Adv Urol 2018;10(11):327-333

34 Rukstalis D, Rashid P, Bogache WK, et al. 24-month durability after crossover to the prostatic urethral lift from randomised, blinded sham. BJU Int 2016;118(Suppl 3):14-22

35 Rieken M, Bachmann A. Update on Greenlight laser vaporization (PVP) 2014. World J Urol 2015;33(4):531-537

36 Jones P, Alzweri L, Rai BP, Somani BK, Bates C, Aboumarzouk OM. Holmium laser enucleation versus simple prostatectomy for treating large prostates: results of a systematic review and meta-analysis. Arab J Urol 2016;14(1):50-58

37 Zell MA, Abdul-Muhsin H, Navaratnam A, et al. Holmium laser enucleation of the prostate for very large benign prostatic hyperplasia ( $\geq 200$ cc) World J Urol 2021;39(1):129-134 